Editorial

\title{
Acknowledgment to Reviewers of Taxonomy in 2021
}

\section{Taxonomy Editorial Office}

Citation: Taxonomy Editorial Office. Acknowledgment to Reviewers of Taxonomy in 2021. Taxonomy 2022, 2, 89-90. https:// doi.org/10.3390/taxonomy2010006

Published: 25 January 2022

Publisher's Note: MDPI stays neutral with regard to jurisdictional claims in published maps and institutional affiliations.

Copyright: $\odot 2022$ by the author. Licensee MDPI, Basel, Switzerland. This article is an open access article distributed under the terms and conditions of the Creative Commons Attribution (CC BY) license (https://creativecommons.org/licenses/by/4.0/).

MDPI AG, St. Alban-Anlage 66, 4052 Basel, Switzerland

Rigorous peer-reviews are the basis of high-quality academic publishing. Thanks to the great efforts of our reviewers, Taxonomy was able to maintain its standards for the high quality of its published papers. Thanks to the contribution of our reviewers, in 2021, the median time to first decision was 15.5 days and the median time to publication was 33.5 days. The editors would like to extend their gratitude and recognition to the following reviewers for their precious time and dedication, regardless of whether the papers they reviewed were finally published:

Abalde Lago, Samuel

Albert, James

Altenburger, Andreas

Ashworth, Matt P.

Ataslar, Ebru

Atherton, Sarah

Barone Lumaga, Maria Rosaria

Barrie, Fred R.

Bassi, Davide

Beauger, Aude

Bilous, Olena

Boufford, David

Brescovit, Antônio Domingos

Brunton, Daniel F.

Bustamante, Danilo Edson

Campbell, David C.

Carmona, Leila

Caruzo, Maria Beatriz Rossi

Chmielewski, Jerry G.

Cianferoni, Fabio

Czerwik-Marcinkowska, Joanna

De Oca, Laura Montes

Desiderato, Andrea

Deslandes, Eric

Falniowski, Andrzej

Forster, Paul

Galea, Horia

Garrouste, Romain

Genkal, Sergey I.

Gholipour, Abbas

Glaw, Frank

Granica, Sebastian

Grismer, Lee

Gu, Junjie
Guilbert, Éric

Heinicke, Matthew

Hendrickx, Michel

Jazdzewska, Anna

Karabanov, Dmitry

Keshavarzi, Maryam

Key, Marcus M., Jr.

Kocot, Kevin M.

Köhler, Jörn

Komnenov, Marjan

Kuchta, Roman

Kunwar, Ripu

Langlet, Dewi

Legalov, Andrey Alexandrovich

Lehnert, Marcus

Lehr, Edgar

Liu, Ho Yih

Manuel, Ballesteros

Mendes, Andrea

Mikhailov, Kirill G.

Myers, Alan

Nogueira Júnior, Miodeli

Perveen, Anjum

Poupin, Joseph

Powell, G. Lawrence

Pratt, Brian

Reilly, Sean B.

Riina, Ricarda

Ronowicz, Marta

Rouhan, Germinal

Rudkovsky, Andrey A. P.

Salino, Alexandre

Schmidt-rhaesa, Andreas

Terry, Irene 
Ueckermann, Eddie

Van Der Maesen, Laurentius J. G.

Vieira, Leandro M.

Wilson, Jeremy D.
Winston, Judith E.

Wynne, Michael J.

Yessoufou, Kowiyou

Zander, Richard 